Available online at www.jmle.org

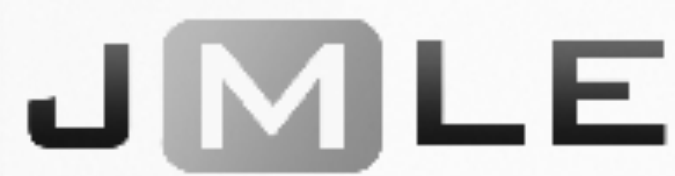

The National Association for Media Literacy Education's

Journal of Media Literacy Education 9 (1), 1 - 21

\title{
Walking the Line between Reality and Fiction in Online Spaces: Understanding the Effects of Narrative Transportation
}

\author{
Sarah Gretter \\ Michigan State University \\ AmanYadav \\ Michigan State University \\ Benjamin Gleason \\ Iowa State University
}

\begin{abstract}
Recent contentions about "fake news" and misinformation online has shed light on the critical need for media literacy at a global scale. Indeed, digital stories are one of the main forms of communication in the 21 st century through blogs, videos-sharing websites, forums, or social networks. However, the line between facts and fiction can often become blurry in these online spaces, and being able to distinguish between reality and fantasy can have important consequences in the lives of young Internet users. Using contemporary examples from news stories, fanfiction, advertising, and radicalization, this article outlines the features, affordances, and real-life implications of digital stories. As a result, we provide recommendations for educators to create awareness and empower students about digital storytelling practices.
\end{abstract}

KEYWORDS: advertising, digital storytelling, fiction, media literacy, narratives, news, propaganda, transmedia, transportation

“There's always room for a story that can transport people to another place." J.K Rowling

From fake news to conspiracy theories, the 2016 U.S. presidential elections raised questions about the effect of online information and the social media echo chambers that seem to characterize today's world of information (Kucharski 2016). This debate has been highlighting the fact that while stories on the Internet can be entertaining, social media platforms are also increasingly used 
for misinformation or propaganda such as targeted advertising (Tuten 2008) or even radicalization (Bloom 2013). It has also emphasized that more than ever, it is essential for educators to equip children and young adults with intellectual tools to detect when the misrepresentation of reality-intentional or not-in digital stories can have consequences in real life (Wilson et al. 2013). Researchers recently showed that out of 7,804 student responses, more than $80 \%$ of middle school students believed that web ads were real news stories, and more than $80 \%$ of high school students had a hard time distinguishing between real and fake photosconcluding that, "overall, young people's ability to reason about the information on the Internet can be summed up in one word: bleak" (Stanford History Education Group 2016, 4). Indeed, not being able to distinguish between reality and fiction online can have dramatic real-life consequences. In the spring of 2014, for example, two 12-year-old girls attempted to impress Slenderman (a fictional character that often appears in online horror stories and as a popular Internet meme) by bringing a friend into a wooded area after a sleepover and stabbing her 19 times (Hanna and Ford 2014). One of the suspected girls told authorities that Slenderman was the leader of a website that they often visited, and that in order to earn his respect, his followers had to kill somebody (Hanna and Ford 2014).

Similar to today's concerns about fake news, the Slenderman case prompted journalists and researchers alike to discuss issues related to the real-life impact of the stories that young Internet users are exposed to in online spaces. Included in these concerns were reflections about how the Internet was an opensource for fiction (Chess and Newsom 2014); how children distinguished between reality and fiction online (Wallace 2014); and how new media technologies provided novel grounds for the distortion of reality (Edwards 2015).

We argue here that an essential step to teaching students to critically assess online content is to first understand how the human mind distinguishes between reality and fiction when being transported in online storytelling spaces. More specifically, we ask: How do digital stories impact youth's reality? This article advances a step in this direction by looking at online stories through the lens of narrative transportation theory. As such, it addresses (i) what makes stories a powerful tool to convey ideas, (ii) how digital storytelling differs from traditional storytelling, and (iii) what educators can do to help students critically assess stories in online spaces. First, we outline the distinguishing features of digital and traditional storytelling and introduce key concepts related to this deeprooted tradition. Next, we provide an overview of the real-world impact of stories on individuals and present insights from research on narrative transportation theory. Third, we outline how the affordances of the Internet contribute to blurring the lines between reality and fantasy in digital storytelling. And finally, we discuss relevant pedagogical implications and recommendations for educators striving to help students gain the critical skills they need to navigate storytelling in today's digital spaces. 


\section{1st Century Storytelling}

Advances in technology have made it easier to access the vicarious knowledge that we covet about the world (Greenfield 2015; Harris and Sanborn 2013). Storytelling in the $21^{\text {st }}$ century evolved as people found new ways to record, share, and consume stories: games, personal experiences, or news, are just few of the examples (Lundby 2008). Today, modern technology has merged the visual with the auditory and the textual, while giving everyone the agency to become their own storyteller and make use of their digital environment for personal purposes (Greenfield 2015). In our technology-saturated lives (Lenhart et al. 2015), the exchange of stories often occurs through popular culture or on websites that offer informal and interactive spaces (Gee 2015; Gleason 2015). This is exemplified by today's youth, who actively participate in digital storytelling on various social media platforms (e.g., blogs, forums, social networks, etc.) on a daily basis (Lenhart et al. 2015). Recent statistics show that more than $94 \%$ of tweens and teens use digital media on a daily basis, including watching online videos, reading, gaming, and interacting on social media; while $34 \%$ of tweens and $28 \%$ of teens write stories, articles or blogs themselves (Rideout 2015).

Although digital stories foster community building through narratives, not being able to distinguish between facts and fantasy in online stories can lead to persuasion. And while this persuasion is not always intentional, propaganda can happen when information, entertainment, and persuasion are intentionally merged to change individuals' behaviors or actions (Hobbs and McGee 2014). As such, the Internet is one the most efficient medium for propaganda activities (Jowett and O'Donnell 2014) where anyone can manipulate the innocence, the absence of knowledge, or the emotional state of the youth in order to suspend their disbelief and incite them to overlook the limitations of a narrative (Coleridge 1984). Figuring out whether information is manipulated to persuade us or not can be a daunting task, and in online spaces filled with stories, young users are particularly at risk. They are at a crucial stage in their growth where biology, cognition, and socio-emotional components of development interact (Reynolds 2012), and they can often turn to social networks for emotional support (Best, Manktelow and Taylor 2014). The paradox of these online youth is that, while they are vulnerable, they are also risk-takers, and are ready to take chances such as connecting with unknown individuals or sharing personal information publicly (White, Gummerum and Hanoch 2015).

Indeed, when children and teens are less satisfied with their "real" life, they tend to view Internet platforms as communicative environments that they value more than their offline life, which can lead to risks related to anonymous communication (Livingstone and Helsper 2007). Green, Chatham and Sestir (2012) reminded us that psychological immersion into someone else's story-also called "narrative transportation"-entails emotionality and attentional focus. Two of their studies suggested that when readers' pre-reading emotional states matched the emotional tone of a narrative, transportation into that narrative was increased. In another study, Green et al. (2004) suggested that individuals could often develop a sense of connection with the people that they encountered in these 
narrative worlds, which reinforced their belonging to a specific community. This connection, a result of their immersion in a specific story world, is a "process that consists of increasing loss of self-awareness and its temporary replacement with heightened emotional and cognitive connections" with a person or a cause (Cohen $2001,251)$. Of course, being transported into a story world is not new. We've experienced it reading novels and comic books, watching our favorite show, and listening to the radio. What is new is youth's constant and involuntary exposure to unfiltered stories in online spaces. The brief history of storytelling provided below underlines the features that make digital storytelling such a unique vehicle for feeling transported into persuasive narrative worlds.

\section{Stories are Everywhere: A Brief History of Digital Storytelling}

From cave paintings to today's social networking sites, human beings have enjoyed sharing their experiences of the world and of their social interactions through narrative forms such as anecdotes, songs, or tales (Gottschal and Wilson 2005). Stories shape our lives: they respond to our need for coherence in the face of perplexing aspects of life experiences (Ochs and Capps 2009), they help us make sense of ourselves and others (Gretter 2015), they convey knowledge we might not have access to otherwise (Gottschall and Wilson 2005), and they enable play, imagination, morality, and other cognitive capacities that define us through the lifespan (Boyd 2009). Through stories, we share fragments of life and communicate with others for multiple purposes such as imparting knowledge, leaving a personal legacy, or simply for entertainment (Zipes 2013). In fact, we naturally think in narrative ways, which sometimes makes it difficult to realize how central stories are to our human experience (Turner 1998).

Stories are considered to be an evolutionary adaptation, so much so that Bruner (1991) argued that "narrative comprehension is among the earliest powers of mind to appear in the young child and among the most widely used forms of organizing human experience" (9). The rich and diverse experiences embedded in narratives are integral to how we learn about our environment and how we come to understand, process, and memorize information (Applebee 1978; Bruner 1991). Stories also allow the transmission of emotions, which are essential in building a sense of belonging with others by giving meaning and personal importance to narrative content (Damasio 1994; Oatley 2002). In the real world, emotions have been shaping our growth since childhood, either through direct experiences or through vicarious ones, such as those mediated by stories (Bartsch and Wellman 1995; Bruner and Olson 1974; Applebee 1978). And while emotions help us understand the world around us and shape how we organize and communicate our own life experiences (Opdahl 2002; Oatley 1992), storytelling enables us to notice, understand, categorize, explain, and manage the emotions generated from our worldly experiences (Kurakin 2010). In other words, we, as human beings, learn through and with stories early in our lives, and we constantly build ourselves through the various narratives that are present around us. And interestingly, our vicarious experiences of the world can be mediated through stories of all kinds, whether they are real or fictional (Coles 1998; Heath 2004; Miller and Moore 1989; Moje 2000). 


\section{Fiction and Facts in Stories}

It is important to recognize that, even if imaginary, fiction plays an essential role in the cognitive and affective processes that influence the way we learn (Applebee 1978). For instance, prior research has already established the strong link between reading bedtime stories to children and the development of literacy skills (Heath 2004), between fiction and empathy (Bal and Veltkamp 2013; Jarvis 2012), between learning from fiction and memory (Marsh et al. 2003), as well as between reading fiction and personal growth in adults (Lawrence and Cranton 2015). Boyd (2009) argued that while factual stories are a way to share relevant information with others, fictional narratives help us understand life experiences and human behaviors. In fact, in a study where participants were asked to label images of human interaction as either real or fictional, Mendelson and Papacharissi (2007) found that participants thought more deeply about images when they thought they were fictional.

Both factual and fictional information share similar goals: communicating knowledge, connecting people, making people laugh, or even antagonizing others. However, while factual stories accomplish these goals using true events or information, fictional stories do so without advancing claims of truthfulness. As a result, overlooking this distinction can have consequences for individuals who accept fiction as facts (Schaeffer 2012). For instance, although the Slenderman case was an extreme example of digital storytelling gone awry, it illustrates the pervasiveness of fictional stories in our daily lives and their influence in shaping our beliefs, perceptions, and attitudes as we learn about the world that surrounds us (Green et al. 2004; Schaeffer 2012). And while no conclusions should be drawn between the effect of fiction and the Slenderman case, it helps us understand the nature of digital communications in online spaces, and how exposure to stories can sometimes create distorted views or misconceptions about reality (Bandura 1994; Potter 2004). These distortions can have consequences in real life, and research shows that whether they come from factual or fictional sources does not seem to matter, as long as the story transports you in its world.

\section{A Powerful Story is One that Transports You}

Regardless of its trustworthiness, what makes a powerful story is its power to transport us in its narrative world. In their description of transportation theory, Green and Brock (2000) proposed that the enjoyment of stories relies more on immersion in a narrative world than on the type of media itself (e.g., television, books, etc.). Through a series of experiments, they demonstrated that the more participants were transported in a story, the more they believed its content to be true. The authors argued that it was the idea of transportation, or "the emotional reactions, mental imagery, and loss of access to real-world information," that made a story persuasive (Green and Brock 2000, 703).

Transportation into a narrative world is an experience that involves cognitive, affective, and imagery involvement in said narrative (Green and Brock 2000). Narrative transportation provides us enjoyment, allows us to escape, to self-transform, and to develop empathy and connection with characters, but can 
also lead to influential persuasion (Green, Brock and Kaufman 2004). This can be explained through the strong affective responses and low levels of critical thinking involved in transportation, which can affect real-world attitudes (Dill 2009, 2013; Escalas 2004; Green and Brock 2000; Green, Strange and Brock 2003; Mazzocco, Green, Sasota and Jones 2010).

Previous research has showed that fictional narrative transportation can significantly influence real-life beliefs (Appel and Richter 2007; Green and Brock 2000; Prentice, Gerrig and Bailis 1997; Strange and Leung 1999; Wheeler, Green, and Brock 1999) and that often, individuals are unable to recognize if the sources of influence for their attitudes came from actual events or fictional ones (Hasher, Goldstein, and Toppin 1977; Johnson, Hashtroudi, and Lindsay 1993; Wyer and Adaval 2004). Gerrig (1993) stated that when we experience fictional stories, we presume the information to be true until we find reasons to disbelieve it. For instance, we do not discredit Harry Potter's use of a magic wand-even though we know these do not exist in real life-because it makes sense within the context of the Harry Potter world. Similarly, teenagers reading stories about Slenderman might not question his existence because they have no proof of his non-existence. Yet, we integrate that knowledge in our mind without always questioning it. Gerrig (1993) precisely reminded us of the power of fiction on real-world actions: although we know that movies are fictional, watching Jaws before going to the beach can certainly impact our behavior while going for a swim in the ocean. As a result, journeys to narrative worlds can sometimes leave individuals changed-or unable to compartmentalize fictional narrative experiences from reality.

\section{Narrative Transportation with Multimedia}

How does narrative transportation function in an age where stories are widely shared online? Gibson (1979) explained that human beings make use of the affordances a specific environment offers them. That is, the interaction between the environment and human beings affords them the opportunity to perform a set of desired actions. In our present case, the affordances of the Internet and digital technologies provide a multimedia dimension to narratives that allow individuals to share their stories through text, images, video, or audio (Hoffmann 2010; Rossiter and Garcia 2010). These affordances are attracting an increasing number of young users who, through their access to technology, have become avid consumers of digital stories in all their forms. With new technologies, narratives can spread across multiple media platforms (i.e., social media, forums, news sites, etc.), which help maintain transportation into said narratives (Ryan 2011). Jenkins (2007) called this phenomenon "transmedia storytelling," the phenomenon of popular stories generating a variety of crossmedia adaptations.

The Slenderman storyline perfectly illustrates this interaction between technology and narrative transportation (Boyer 2013). Slenderman, which was created in a 2009 Photoshop context, quickly became a popular meme that spread to YouTube videos, horror stories, and games (Trammel and Gilbert 2014). Peck (2015) explained how the multimodality of the character (i.e., oral, visual, textual) was essential to understanding how individuals started diffusing the Slenderman 
legend as a digital performance that used online and digital resources to transmit the emotions associated with the character and its stories. These transmedia practices help immerse users in story worlds through their participation in responding to these narratives (Green, Brock and Kaufman 2004; Jenkins 2009). Jenkins (2007) proposed that "transmedia storytelling represents a process where integral elements of a fiction get dispersed systematically across multiple delivery channels for the purpose of creating a unified and coordinated entertainment experience. Ideally each medium makes its own unique contribution to the unfolding of the story" (1). In the following section, we explore how these digital stories can further blur the line between facts and fiction in online spaces.

\section{Untangling the Link between Narrative Transportation and Propaganda}

We used the Slenderman fanfiction example as a starting point to show how online storytelling spaces could have real-world implications. Gee (2011) labeled these informal communities driven by shared interests "affinity spaces" (69). One such example of these community is Reddit, a social news aggregation community where users vote to move content up or down to appear at the top of a category (Chess and Newton 2014; Gee 2011). The participatory phenomenon of fanfiction is another example, where writers and readers digitally gather and connect around storytelling activities. For instance, the two teenagers accused of stabbing their friend to impress the fictional character Slenderman were part of a fanfiction website called Creepypasta Wiki. The term was derived from a play on word from "copy and paste," and is a type of horror fiction that mimics the style of news or true crime stories (Hanna and Ford 2014). Passionate affinity spaces like the writers' community Creepypasta, among other social media or blogging websites, showcase users' deep passion for a common theme, endeavor, or even character that transports them to a narrative world-even if fictional (Gee 2011). These story worlds, with the help of technological tools, heighten narrative transportation and seduce youth who have increasing access and presence on the Internet.

In addition to fostering transportation through multimedia and youth participation, the Internet can sometimes blur the boundaries between reality and fiction, rendering the distinction between factual and fictional information more difficult (Fuchs 2007). This blurriness can facilitate propaganda - the process by which information, entertainment, and persuasion are blended to affect individuals' thoughts (Hobbs and McGee 2014). This is particularly troubling for the youth, who might lack critical knowledge about propaganda and thus overlook the limitations of a story (Jowett and O'Donnell 2014). For instance, the convergence of media through technology has facilitated this haze through the development of concepts such as "docudramas," "edutainment," and "infotainment," which have gained popularity over the years (Thussu 2008). Mohammed (2012) proposed that with the extensive diffusion of information facilitated by advances in communication technologies, people often struggle to tell the difference between facts and opinion, entertainment, and outright disinformation. As a result, online stories can be perceived as either fictional or factual; with the consequence that fictional content may be processed and 
interpreted as factual (Fuchs 2007). The difficulty in distinguishing between genres is further complicated by the fact that information is increasingly storified by mixing storytelling with truth-telling to attract audiences and increase ratings (Park 2006).

An instance of narrative blurriness that can greatly impact youth' realities is through online calls for activism. Social media have become platforms for activists to have a voice, receive funds, or simply create awareness (Jones and Wayland 2013). The Kony 2012 campaign, which aimed to help stop brutalities in central Africa brought by Joseph Kony and the Lord's Resistance Army, is often referred to as an example of "slacktivism," the phenomenon in which people share posts about an issue on social media, such as \#StopKony on Twitter. And yet, the campaign video reached 50 million views and attracted thousands of dollars in donations on the first day-popular primarily with U.S. viewers under 25 years old (Kavanagh, Ojalvo and Schulten 2012). For Jenkins (2012), the Kony 2012 campaign represented storytelling-based activism through transmedia mobilization, where the activist group's presence was built on the Internet across platforms and narratives. Transmedia storytelling in Kony2012 integrated elements of fiction and spread them across different media to emphasize "world building" where transported audiences were engaged in sharing information across media (Jenkins 2007). This mobilization across media is what led the Kony2012 campaign to have such a large impact on the youth following it. While a thorough analysis of what the campaign did or did not accomplish goes beyond the scope of this paper, the phenomenon is a clear reminder of how a documentary-story can transport the youth and call for action in real life.

Another, distinct form of digital storytelling that intentionally uses the effects of narrative transportation to persuade users is online advertising-also called "native advertising" or "sponsored content." Thanks to advances in technology, ads are increasingly transformed as to not appear as ads at all (Clemons and Wilson 2015). For instance, in a study looking at luxury brand advertising effectiveness through narrative transportation, Kim, Lloyd and Cervellon (2016) showed that across cultures, participants were "transported through their enactment with deeply held, implicit myths and fantasies" (311). Their study revealed that narrative transportation storylines that were based on implicit messages were indeed more likely to engage consumers (Kim, Lloyd and Cervellon, 2016). In another study, Brechman and Purvis (2015) used a national sample of viewers of Super Bowl XLV (2011) and XLVI (2012) where half of commercials were found to use a narrative approach. The authors measured the effectiveness of advertising transportation through brand recall and belief change. While the results showed that some individuals might be more receptive to narrative transportation than others, they concluded that narrative transportation in advertising was a powerful tool to suspend consumers' disbelief and impact attitudes (Brechman and Purvis 2015).

When advertising messages are fashioned into short narratives that transport viewers in order to generate strong affective response and low levels of critical thinking, they can then effectively impact real-world attitudes and positive message evaluation (Brechman and Purvis 2015; Chang 2009; Escalas 2004; 
Phillips and McQuarrie 2010; Wang and Calder 2006). For example, actor Zach Galifianakis' Funny or Die interview series - a spoof of celebrity interview shows called "Between Two Ferns"-featured President Obama in one of its episodes. Challenging the traditional PSA genre, the White House was actually attempting to reach a young audience and encourage them to get health insurance before the enrollment deadline for the Affordable Care Act (Johnson 2014). By blending promotion with popular culture and humor, the video reached two million views after only three hours online, and traffic on the Healthcare.gov website increased $40 \%$ the same day, resulting in the show being the top referrer to the government website (Yang 2014).

The lack of distinction between narrative genres in multimedia stories can greatly influence how users process information, especially when entertainment is created to attract audiences and increase ratings by adapting information and facts into attractive storylines (Elliott and King 2010; Mendelson and Papacharissi 2007). For instance, two studies investigated the effect of fact or fiction labeling on the processing of persuasive communication. When labeled as fact rather than fiction, readers appeared to be more critical than when labeled as fictional, even if the stories were not real (Green, Garst, Brock and Chung 2006). Similarly, Altmann, Bohrn, Lubrich, Menninghaus and Jacobs (2014) also found that paratextual information such as fact vs. fiction labels to a story had implications for narrative processing. In their fMRI study, the two labels prompted different neural activation patterns: factual texts activated comprehension and information gathering, while fictional texts activated a simulation of the imagined events. Altogether, these studies implied that when fictional narratives are not labeled as such, they do not trigger critical responses from readers or viewers.

For that reason, a worrisome area for online propaganda through narrative transportation exists in the realm of radicalization-the process of adopting extreme political, social, or religious ideals. Social media sites have progressively become anonymous and decentralized radicalizing spaces (Bloom 2013; Matusitz 2013) where technology is used to transport individuals into persuasive narratives. Social networks and forums are used to diffuse videos, computer games, music clips, memes, or photos (Bott 2009; Conway and McInerney 2008), and rely more on visuals than text-based narratives to relay emotive media messages, which mainstream media also help spread through viral videos (Zelin 2015). Some groups even use cartoon-style designs, colorful children's stories, or Disney-like cartoon characters to appeal to young audiences (Weimann 2008). In his metaanalysis of terrorist narratives, Braddock (2012) proposed that extremist narratives play an essential role in changing beliefs and attitudes that can lead to radicalization. Stevens and Neumann (2009) reiterated that "the Internet can be used by extremists to illustrate and reinforce ideological messages and/or narratives. Through the Internet, potential recruits can gain access to visually powerful video and imagery which appear to substantiate the extremists' political claims" (1). Extremist groups (e.g., Al-Qaeda, ISIS) have been using narratives to diffuse their ideas through rap videos, magazines, images and other media types, and to present their ideas as an option for the youth to express their dissatisfaction with the current status quo (Klausen 2015). Venhaus (2010) showed that 
radicalization targets are young individuals in search of a sense of purpose and mission in life, and these narratives provide a platform to express that purpose: "revenge seekers need an outlet for their frustration, status seekers need recognition, identity seekers need a group to join, and thrill seekers need adventure" (1). As such, these radicalization stories aim at highlighting precepts of traditional storytelling like notions of brotherhood, sacrifice, or the sense of belonging, all the while appealing to individuals' interest in popular media (Gates and Podder 2015; Payne 2009).

From fanfiction to advertisement, activism to radicalization, people use stories to engage with others, build communities, persuade people, and find an escape from everyday lives. How can educators prepare students to critically assess the stories they find in these online spaces? In our final section, we explore ways that teachers can help students counter narrative transportation through narrative-based pedagogies that highlight the core principles of media literacy.

\section{Recommendations for Educators}

Stories are powerful intellectual achievements that allow us to make sense of our experiences amidst confusing events in our lives, while also supporting language play that is creative and expressive. At the same time, stories build connections between ourselves, others, and imagined worlds beyond our immediate environment. And while the use of stories, and narratives in general can facilitate educational outcomes such as the development of literacy skills (Heath 2004), empathy (Jarvis 2012), memory (Marsh et al. 2003), and information sharing (Boyd 2009), the narrative transportation that occurs through storytelling reveals some of the unanticipated challenges of Internet-enabled teaching and learning in the $21^{\text {st }}$ century. Narrative transportation suggests that the engaging, immersive experience of a story, which can facilitate strong affective responses and low levels of critical thinking, can have unintended negative consequences, especially in online spaces. Fanfiction, online advertising and radicalization provide examples of how young individuals face challenges in determining the blurred line between facts and fiction. While these challenges are significant, educators should not shy away from using the affordances of digital storytelling for teaching. This section presents three recommendations for integrating digital storytelling into teaching and learning settings that highlight the core principles of media literacy put forward by the National Association for Media Literacy Education (NAMLE) (2017).

\section{Emphasizing Literary and Narrative-based Pedagogy}

Countering the "narrative turn" in the humanities and social sciences, the Common Core Standards emphasize the use of informational texts and close reading strategies at the expense of interpretative forms of literary and historical analysis. For example, the model English lesson offered by the Common Core Standards includes an informational text typically found in a history or social studies class, the Gettysburg Address, rather than a typical work of fiction (Hechinger Report 2014). Rejecting analysis of the social, cultural, political, and historical context of the Gettysburg Address, the Common Core example arms 
students only with the strategy of informational close reading. In light of current pedagogical practices popularized through the Common Core, we propose a deliberate return to literary and narrative-based pedagogy. A narrative-based pedagogy aims to increase students' media and information literacy skills (Wilson et al. 2013) through a focus on the cognitive, affective, and social dimensions actualized through this mode of teaching and learning. Put simply, a narrativebased pedagogy aims to counter the decontextualized and atomized nature of reading and writing in schools today.

Beyond the close reading of isolated texts, narrative-based pedagogy emphasizes holistic practices of creation, critique, and interpretation. Meaning is not just found "in" the texts, but in the cultural, social, and cognitive practices that facilitated the creation of these texts. Based on the idea that stories can organize and motivate students, educators can frame curricula around narratives to support learning. Narratives create memorable worlds, experiences, and ways of interacting with the world; and a narrative-based pedagogy relies on the power and possibility of narrative to compel analysis (Bruner 1991), rather than standardized tests and the organizing structure of school to do so. This kind of pedagogy seeks to enable students to interact productively with a variety of narratives through situated learning (Lave and Wenger 1991). Narrative-based pedagogy thus reflects the following core principles of media literacy education (NAMLE 2017):

- Media Literacy Education expands the concept of literacy to include all forms of media (i.e., reading and writing).

- Media Literacy Education builds and reinforces skills for learners of all ages. Like print literacy, those skills necessitate integrated, interactive, and repeated practice.

\section{Developing Analytical Competencies around Transmedia Storytelling} Jenkins (2007) described the idea of telling digital stories across multiple platforms (i.e., Facebook, Twitter, and YouTube) as a unified experience in which each specific platform contributes another dimension to the overall storytelling experience. Yet, anecdotes such as the Slenderman example, and research that found challenges in students mistaking fictional events for factual ones, suggest difficulties in the interpretation and meaning-making that come in transmedia environments. Transmedia environments complicate the act of interpretation: as the number of media increase, so does the possibility of misinterpretation (Alper and Herr-Stephenson 2013). Original contexts that provide useful information for interpretation disappear as stories are told in multiple online spaces. The aim for a unified meaning-making experience can therefore turn into a disjointed or decontextualized experience. As a result, teachers need to provide experiences for students to develop analytical competencies in transmedia narratives in order to challenge unsophisticated interpretative practices, including the popular tendency of presuming something is true until it is proven false.

Through these practices, students can gain opportunities to develop metaawareness and knowledge of rhetorical practices (Hobbs 2010; Hull 2003; Avila 
and Moore 2012). With the need to understand media effectiveness, learning opportunities can arise as students link their analysis to their own personal stories. By becoming effective storytellers themselves, they can learn to analyze the elements that compose a well-constructed persuasive story, and use it to derive their own meaning from media content. For instance, Kearney (2011) showed that learner-generated digital storytelling often leads to the development of critical thinking because it allows learners to express personal emotions through autobiographical explorations of a variety of topics and modes of communication (Kearney 2011). As such, contextualizing digital storytelling helps fulfill additional NAMLE (2017) principles:

- Media Literacy Education requires active inquiry and critical thinking about the messages we receive and create.

- Media Literacy Education affirms that people use their individual skills, beliefs and experiences to construct their own meanings from media messages.

\section{Viewing Digital Storytelling as Situated Learning}

As a way to create persuasive, multimedia narratives, the inclusion of digital storytelling and media literacy in educational settings has the potential to transform the process of teaching and learning. Conceptualizing digital storytelling and media literacy as situated learning means that narrative-based pedagogy exists in an "interested, intersubjective, negotiated social interaction" (Lave and Wenger 1991, 67). Rather than conceiving of digital storytelling as mere opportunity to develop individual cognitive skills through mediatized stories that reflect "real world" activities, situated learning assumes that cognition and communication "are situated in the historical development of ongoing activity" (Lave and Wenger 1991, 67); that is, digital storytelling can be part of an active social practice that challenges, contributes, and critiques the "real world" (Jolls and Wilson 2014). Through a focus on centering student experiences with digital stories, narrative-based pedagogy works because it counters the "commoditization" of education, in which students often feel alienated and disengaged from school, as a result of standardized curricula and student stratification by perceived ability (Lave and Wenger 1991; Giroux and McLaren 2014).

Unlike in the pedagogical paradigm of the Common Core, narrative-based pedagogy aims to situate teaching and learning as activity in "real world" communities of practice. Teachers aim to make connections between teaching and learning in school and participatory learning. By situating teaching and learning in the real world of student experiences, language, and culture, this pedagogy takes advantage of student histories of participation in democratic youth-initiated activities (Paris 2010; Kirkland 2008; Gleason 2015). In a narrative-based pedagogy conceptualized as situated learning, students become masterful storytellers through their digital media participation. Through participation, students develop media literacy, expertise, and agency that have the potential to renegotiate power relations in the classroom (Garcia et al. 2015; Emdin 2016). 
Thus, focusing on the narrative aspect of media literacy may become a powerful pedagogical tool for teachers and students to situate learning in its full, social, cultural, and aesthetic practices - while achieving the last two NAMLE (2017) core principles:

- Media Literacy Education recognizes that media are a part of culture and function as agents of socialization.

- Media Literacy Education develops informed, reflective and engaged participants essential for a democratic society.

\section{Conclusion}

Throughout this paper, examples like Slanderman, Reddit, or Kony 2012 have highlighted the importance of narrative transportation, particularly for the youth in today's hyper-connected online world. More importantly, they served as springboard to emphasize the need to integrate narrative-based pedagogy in educational settings. In a time of fake news, conspiracy theories, and edutainment, the necessity for media literacy is more pressing than ever. Students need the ability to critically assess the stories they have access to in online spaces, and educators need to be able to teach these skills. Almost ten years ago, Kellner and Share (2005) asserted that "educators need to move the discourse beyond the stage of debating whether or not critical media literacy should be taught, and instead focus energy and resources on exploring the best ways for implementing it" (59). Today, as we move from teaching with media and technology to teaching about media and technology (Tiede, Grafe and Hobbs 2015), media literacy needs to become a reality in schools. Countering narrative transportation through narrative-based pedagogies that reinforce students' media literacy is an effort that needs to be undertaken in our educational system-particularly in times of political and social transformations.

\section{References}

Alper, Meryl \& Herr-Stephenson, Rebecca. 2013. "Transmedia Play: Literacy across Media." Journal of Media Literacy Education 5 (2): 366-369.

Altmann, Ulrike, Isabel C. Bohrn, Oliver Lubrich, Winfried Menninghaus, and Arthur M. Jacobs. 2014. "Fact vs. Fiction: How Paratextual Information Shapes our Reading Processes." Social Cognitive and Affective Neuroscience 9 (1): 22-29.

Appel, Markus, and Tobias Richter. 2007. "Persuasive Effects of Fictional Narratives Increase over Time.” Media Psychology 10 (1): 113-134.

Applebee, Arthur N. 1978. The Child's Concept of Story: Ages Two to Seventeen. Chicago, IL: The University of Chicago Press.

Avila, JuliAnna, and Michael Moore. 2012. "Critical Literacy, Digital Literacies, and Common Core State Standards: A Workable Union?" Theory into Practice 51 (1): 27-33. 
Bal, P. Matthijs, and Martijn Veltkamp. 2013. "How does Fiction Reading influence Empathy? An Experimental Investigation on the Role of Emotional Transportation.” PloS One 8(1): e55341.

Bandura, Albert. 1994. "Social cognitive theory of mass communication." In Media Effects: Advances in Theory and Research, edited by Jennings Bryant and Mary Beth Oliver, 61-90. Hillsdale, NJ: Erlbaum.

Bartsch, Karen, and Henry M. Wellman. 1995. Children Talk about the Mind. Oxford: Oxford University Press.

Best, Paul, Roger Manktelow, and Brian Taylor. 2014. “Online Communication, Cocial Media and Adolescent Well-being: A Systematic Narrative Review." Children and Youth Services Review 41: 27-36.

Bloom, Mia. 2013. "In Defense of Honor: Women and Terrorist Recruitment on the Internet." Journal of Postcolonial Studies 4 (1): 150-195.

Bott, Catherine. 2009. The Internet as a Terrorist Tool for Recruitment \& Radicalization of Youth. DHS report. Retrieved from: http://www.homelandsecurity.org/docs/reports/Internet_Radicalization.pdf

Boyer, Tina M., 2013. "The Anatomy of a Monster: The Case of Slenderman." Preternature: Critical and Historical Studies on the Preternatural, 2(2): 240-261.

Boyd, Brian. 2009. On the Origin of Stories: Evolution, Cognition, and Fiction. Cambridge, MA: Harvard University Press.

Braddock, Kurt. H. (2012). Fighting Words: The Persuasive Effect of Online Extremist Narratives on the Radicalization Process. (Doctoral dissertation, The Pennsylvania State University).

Brechman, Jean Marie, and Scott C. Purvis. 2015. "Narrative, Transportation and Advertising." International Journal of Advertising 34 (2): 366-381.

Bruner, Jerome. 1991. "The Narrative Construction of Reality." Critical Inquiry 18 (1): 1-21.

Bruner, Jerome S., and David R. Olson. 1974. "Learning through Experience and Learning through Media." In Media and Symbols: The Forms of Expression, Communication, and Education, edited by David R. Olson, 20-38. Chicago: University of Chicago Press.

Chang, Chingching. 2009. “"Being Hooked' by Editorial Content: The Implications for Processing Narrative Advertising." Journal of Advertising 38 (1): 21-34.

Chess, Shira, and Eric Newsom. 2014. Folklore, Horror Stories, and the SlenderMan: The Development of an Internet Mythology. New York, NY:Palgrave Macmillan.

Clemons, Eric K., and Josh Wilson. 2015. 'Students' and parents' Attitudes towards Online Privacy: An International Study." System Sciences: 48444853.

Cohen, Jonathan. 2001. "Defining Identification: A Theoretical Look at the Identification of Audiences with Media Characters." Mass Communication \& Society 4: 245-264.

Coleridge, Samuel T. 1984. Biographia Literaria, or, Biographical Sketches of my Literary Life and Opinions. Princeton, NJ: Princeton University Press. 
Coles, Robert. 1998. “The Moral Intelligence of Children.” Family Court Review 36 (1): 90-95.

Stevens, Tim and Peter R. Neumann. 2009. Countering Online Radicalisation: A Strategy for Action. London: International Centre for the Study of Radicalisation and Political Violence. Retrieved from: https://cst.org.uk/docs/countering_online_radicalisation1.pdf

Conway, Maura, and Lisa McInerney. 2008. "Jihadi Video and Autoradicalisation: Evidence from an Exploratory YouTube Study.” Retrieved from: http://doras.dcu.ie/2253/2/youtube_2008.pdf

Damasio, Antonio R. 1994. Descartes' Error: Emotion, Reason, and the Human Brain. New York, NY: Putnam.

Dill-Shackleford, Karen E. 2009. How Fantasy Becomes Reality: Seeing through Media Influence. Oxford: Oxford University Press.

Dill, Karen E. 2013. The Oxford Handbook of Media Psychology. Oxford: Oxford University Press.

Edwards, Justin D. 2015. Technologies of the Gothic in Literature and Culture: Technogothics. New York, NY: Routledge.

Elliott, Deni, and Cynthia M. King. 2010. "Tall tales: Ethical storytelling in the age of infotainment." In The Ethics and Entertainment: Essays on Media Culture and Media Morality, edited by Borden, Sandra, and Howard Good, 101-119. Jefferson, NC: McFarland.

Emdin, Christopher. 2016. For White Folks Who Teach in the Hood... and the Rest of Y'all Too: Reality Pedagogy and Urban Education. Boston, MA:Beacon Press.

Escalas, Jennifer E. 2004. "Imagine Yourself in the Product: Mental Simulation, Narrative Transportation, and persuasion.” Journal of Advertising 33 (2): 37-48.

Fuchs, Christian. 2007. Internet and Society: Social Theory in the Information Age. New York, NY: Routledge.

Garcia, Antero, Nicole Mirra, Ernest Morrell, Antonio Martinez, and D'Artagnan Scorza. 2015. "The Council of Youth Research: Critical Literacy and Civic Agency in the Digital Age." Reading \& Writing Quarterly 31 (2):151-167.

Gates, Scott, and Sukanya Podder. 2015. "Social Media, Recruitment, Allegiance and the Islamic State." Perspectives on Terrorism 9 (4): 107-116.

Gee, James P., and Elisabeth R. Hayes. 2011. Language and Learning in the Digital Age. New York, NY: Routledge.

Gee, James P. 2015. "Accountable Talk and Learning in Popular Culture: The Game/affinity Paradigm.” Socializing Intelligence through Academic Talk and Dialogue: 191-198.

Gerrig, Richard. J. 1993. Experiencing Narrative Worlds: On the Psychological Activities of Reading. New Haven, CT: Yale University Press.

Gibson, James J. 1979. The Ecological Approach to Visual Perception. Boston, MA: Houghton Mifflin.

Giroux, Henry A., and Peter McLaren. 2014. Between Borders: Pedagogy and the Politics of Cultural Studies. New York: Routledge. 
Gleason, Benjamin. 2015. "New Literacies Practices of Teenage Twitter Users." Learning, Media and Technology: 1-24.

Gottschall, Jonathan, and David Sloan Wilson. 2005. The Literary Animal: Evolution and the Nature of Narrative. Evanston, IL: Northwestern University Press.

Green, Melanie C., Christopher Chatham, and Marc A. Sestir. 2012. "Emotion and Transportation into Fact and Fiction." Scientific Study of Literature 2(1): 37-59.

Green, Melanie C., Jeffrey J. Strange, and Timothy C. Brock. 2003. Narrative Impact: Social and Cognitive Foundations. New York: Taylor \& Francis.

Green, Melanie C., and Timothy C. Brock. 2000. "The Role of Transportation in the Persuasiveness of Public Narratives." Journal of Personality and Social Psychology 79: 701-721.

Green, Melanie C., Jennifer Garst, Timothy C. Brock, and Sungeun Chung. 2006."Fact versus Fiction Labeling: Persuasion Parity despite Heightened Scrutiny of Fact." Media Psychology 8 (3): 267-285.

Green, Melanie C., Timothy C. Brock, and Geoff F. Kaufman. 2004."Understanding Media Enjoyment: The Role of Transportation into Narrative Worlds.” Communication Theory, 14 (4): 311-327.

Greenfield, Susan. 2015. Mind Change: How Digital Technologies are Leaving their Mark on Our Brains. London: Random House.

Gretter, Sarah. 2015. "From the Novel to Digital Storytelling: Dialogue, Identity, and the Fictionalization of Reality." Letras Hispanas 11: 212-221.

Hanna, Jason, and Dana Ford. 2014. "Twelve-year-old Wisconsin Girl Stabbed 19 Times; Friends Arrested." CNN. Retrieved from: http://www.cnn.com/2014/06/03/justice/wisconsingirlstabbed/index.html?hpt=hp_t1

Harris, Richard J., and Fred W. Sanborn. 2013. A Cognitive Psychology of Mass Communication. New York: Routledge.

Hasher, Lynn, David Goldstein, and Thomas Toppino. 1977. "Frequency and the Conference of Referential Validity." Journal of Verbal Learning and Verbal Behavior 16: 107-122.

Heath, Shirley B. 2004. "What no Bedtime Story Means.” Literacy: Major Themes in Education 1:168.

Hechinger Report. 2014. The Common Core English Standards: Content and Controversy. Retrieved from: http://www.usnews.com/news/specialreports/articles/2014/02/25/the-common-core-english-standards-contentand-controversy

Hobbs, Renee. 2010. Digital and Media Literacy: A Plan of Action. The Aspen Institute. Retrieved from: http://www.knightcomm.org/digital-and-medialiteracy-a-plan-of-action/

Hobbs, Renee, and Sandra McGee. 2014. "Teaching about Propaganda: An Examination of the Historical Roots of Media Literacy." Journal of Media Literacy Education 6 (2): 56-67.

Hoffmann, Christian R. 2010. Narrative Revisited: Telling a Story in the Age of New Media. Amsterdam: John Benjamins. 
Hull, Glynda A. 2003. "At Last,Youth Culture and Digital Media: New Literacies for New Times." Research in the Teaching of English 38 (2): 229-233

Jarvis, Christine. 2012. "Fiction, Empathy and Lifelong Learning." International Journal of Lifelong Education 31 (6): 743-758.

Jenkins, Henry. 2007. “Transmedia Storytelling.” Confessions of an Aca-fan . Retrieved from: http://henryjenkins.org/2007/03/transmedia_storytelling_101.html

Jenkins, Henry. 2009. Confronting the Challenges of Participatory Culture:Media Education for the 21st Century. Cambridge, MA: MIT Press.

Jenkins, Henry. 2012. "Contextualizing \#Kony2012: Invisible Children, Spreadable Media, and Transmedia Activism." Retrieved from: http://henryjenkins.org/2012/03/contextualizing_kony2012_invis.html

Johnson, Marcia K., Shahin Hashtroudi, and D. Stephen Lindsay. 1993. "Source Monitoring." Psychological Bulletin 14: 3-28.

Johnson, Ted. 2014. "How Funny or Die got President Obama on Zach Galifianakis' 'Between Two Ferns"'. Retrieved from: http://variety.com/2014/digital/news/president-obama-on-zachgalifianakis-between-two- ferns-watch-1201129329/

Jolls, Tessa and Wilson, Carolyn. 2014. "The Core Concepts: Fundamental to Media Literacy Yesterday, Today and Tomorrow" Journal of Media Literacy Education 6 (2): 68 -78.

Jones, Christopher and Wayland, Kent. 2013. Activism or Slacktivism? The Role of Social Media in Effecting Social Change. Research Paper. School of Engineering and Applied Science: University of Virginia.

Jowett, Garth S., and Victoria O'Donnell. 2014. Propaganda \& Persuasion. Thousand Oaks, CA: Sage Publications.

Kavanagh, Sarah, Ojalvo, Holly E., \& Schulten, Katherine. 2012. “Activism or Slacktivism? The 'Stop Kony' Campaign as a Teachable Moment." Retrieved from: http://learning.blogs.nytimes.com/2012/03/13/activismor-slactivism-the-kony-2012- campaign-as-a-teachable-moment/

Kearney, Michael. 2011. “A Learning Design for Student-generated Digital Storytelling." Learning, Media and Technology 36 (2): 169-188.

Kellner, Douglas, and Jeff Share. 2005. "Toward Critical Media Literacy: Core Concepts, Debates, Organizations, and Policy." Discourse: Studies in the Cultural Politics of Education 26 (3): 369-386.

Kim, Jae-Eun, Stephen Lloyd, and Marie-Cécile Cervellon. 2016. "Narrative Transportation Storylines in Luxury Brand Advertising: Motivating Consumer Engagement." Journal of Business Research 69 (1): 304-313.

Kirkland, David. 2008. "Shaping the Digital Pen: Media Literacy, Youth Culture and MySpace." Youth Media Reporter 2 (4): 188-200.

Klausen, Jytte. 2015. "Tweeting the Jihad: Social Media Networks of Western Foreign Fighters in Syria and Iraq." Studies in Conflict \& Terrorism 38:1 22.

Kucharski, Adam. 2016 "Post-truth: Study Epidemiology of Fake News."Nature 540, 7634: 525-525. 
Kurakin, Dmitry. 2010. "Literature as a Meaningful Life Laboratory." Integrative Psychological and Behavioral Science 44 (3): 227-234.

Lave, Jean, and Etienne Wenger. 1991. Situated Learning: Legitimate Peripheral Participation. Cambridge, UK: Cambridge University Press.

Lawrence, Randee Lipson, and Patricia Cranton. 2015. A Novel Idea: Researching Transformative Learning in Fiction. Boston, MA: Springer.

Lenhart, Amanda, Maeve Duggan, Andrew Perrin, Renee Stepler, Harrison Rainie, and Kim Parker. 2015. Teens, Social Media and Technology Overview 2015. Washington DC: Pew Research Center. Retrieved from: http://www.pewinternet.org/files/2015/04/PI_TeensandTech_Update2015 _0409151.pdf

Livingstone, Sonia, and Ellen J. Helsper. 2007. "Taking Risks when Communicating on the Internet: The Role of Offline Social-psychological Factors in Young People's Vulnerability to Online Risks." Information, Communication \& Society 10 (5): 619-644.

Lundby, Knut. 2008. "Introduction: Digital storytelling, Mediatized Stories.” In Digital Storytelling, Mediatized Stories: Self-Representations in New Media, edited by Knut Lundby, 1-20. New York, NY: Peter Lang.

Marsh, Elizabeth J., Michelle L. Meade, and Henry L. Roediger III. 2003."Learning Facts from Fiction." Journal of Memory and Language 49 (4): 519-536.

Matusitz, Jonathan A. 2013. Terrorism \& Communication: A Critical Introduction. Thousands Oaks, CA: Sage.

Mazzocco, Philip J., Melanie C. Green, Jo A. Sasota, and Norman W. Jones. 2010. "This Story is Not for Everyone: Transportability and Narrative Persuasion.” Social Psychological and Personality Science 1 (3): 361-368.

Mendelson, Andrew L., and Zizi Papacharissi. 2007. "Reality vs. Fiction: How Defined Realness Affects Cognitive \& Emotional Responses to Photographs." Visual Communication Quarterly 14 (4): 231-243.

Miller, Peggy J., and Barbara Byhouwer Moore. 1989. "Narrative Conjunctions of Caregiver and Child: A Comparative Perspective on Socialization through Stories." Ethos 17 (4): 428-449.

Mohammed, Shaheed Nick. 2012. The (Dis) Information Age: The Persistence of Ignorance. New York: Peter Lang.

Moje, Elizabeth B. 2000. “'All the Stories that we Have': Adolescents' Insights about Literacy and Learning in Secondary Schools." Kids InSight, K-12. Newark, DE: International Reading Association.

National Association for Media Literacy Education. Core Principles of Media Literacy Education in the United States. Retrieved from: https://namle.net/publications/core-principles.

Oatley, Keith. 1992. Best Laid Schemes: The Psychology of the Emotions. Cambridge: Cambridge University Press.

Oatley, Keith. 2002. "Emotions and the Story Worlds of Fiction." In Narrative Impact: Social and Cognitive Foundations, edited by Melanie C. Green, Jeffrey J. Strange, and Timothy C. Brock, 39-69. New York, NY: Erlbaum. 
Ochs, Elinor, and Lisa Capps. 2009. Living Narrative: Creating Lives in Everyday Storytelling. Cambridge, MA: Harvard University Press.

Opdahl, Keith M. 2002. Emotion as Meaning: The Literary Case for How We Imagine. Lewisburg: The Rosen Publishing Group.

Paris, Django. 2010. “Texting Identities: Lessons for Classrooms from Multiethnic Youth Space.” English Education 42 (3): 278-292.

Park, Jungsik. 2006. Storytelling and Truthtelling: Discursive Practices of News Storytelling in Truman Capote, Norman Mailer, and John Hersey" (Doctoral dissertation, Texas A\&M University).

Payne, Kenneth. 2009. "Winning the Battle of Ideas: Propaganda, Ideology, and Terror." Studies in Conflict \& Terrorism 32:109-128.

Peck, Andrew. 2015. "Tall, Dark, and Loathsome: The Emergence of a Legend Cycle in the Digital Age." Journal of American Folklore 128 (509): 333348.

Phillips, Barbara J., and Edward F. McQuarrie. 2010. "Narrative and Persuasion in Fashion Advertising." Journal of Consumer Research 37 (3): 368-392.

Potter, W. James. 2004. Theory of Media Literacy: A Cognitive Approach. Thousand Oaks, CA: Sage.

Prentice, Deborah A., Richard J. Gerrig, and Daniel S. Bailis. 1997. "What Readers Bring to the Processing of Fictional Texts." Psychonomic Bulletin \& Review 4: 416-420.

Reynolds, Helen. 2012. "Adolescent Vulnerability to Risk Online: The Role of Attachment and Peer Relationships." (Doctoral dissertation, University of London).

Rideout, Vicky. 2015. The Common Sense Census: Media Use by Tweens and Teens. Common Sense Media Research. Retrieved from: https://www .commonsensemedia.org/research/the-common-sense-censusmedia-use-by-tweens-and-teens

Rossiter, Marsha, and Penny A. Garcia. 2010. "Digital Storytelling: A New Player on the Narrative Field." New Directions for Adult and Continuing Education 126: 37-48.

Ryan, Marie-Laure. 2011. "Narration in Various Media.” In The Living Handbook of Narratology, edited by Peter Hühn et al. Hamburg: Hamburg University. Retrieved from: http://www.lhn.unihamburg.de/article/narration-various-media

Schaeffer, Jean-Marie. 2012. "Fictional vs. Factual Narration." In The Living Handbook of Narratology, edited by Peter Hühn et al. Hamburg: Hamburg University. Retrieved from: http://www.lhn.unihamburg.de/article/fictional-vs-factual-narration

Stanford History Education Group. 2016. "Evaluating Information: The Cornerstone of Civic Online Reasoning," Retrieved from: https://sheg.stanford.edu/upload/V3LessonPlans/Executive\%20Summary \%2011.21.16.pdf

Strange, Jeffrey J., and Cynthia C. Leung. 1999. "How Anecdotal Accounts in News and in Fiction can Influence Judgments of a Social Problem's 
Urgency, Causes, and Cures." Personality and Social Psychology Bulletin 25: 436-449.

Thussu, Daya Kishan. 2008. News as Entertainment: The Rise of Global Infotainment. Thousand Oaks, CA: Sage.

Tiede, Jennifer, Silke Grafe, and Renee Hobbs. 2015. "Pedagogical Media Competencies of Preservice Teachers in Germany and the United States: A Comparative Analysis of Theory and Practice." Peabody Journal of Education 90 (4): 533-545.

Trammell, Aaron and Gilbert, Anne. 2014. "Extending Play to Critical Media Studies." Games and Culture, 9 (6): 391-405.

Turner, Mark. 1998. The Literary Mind. New York: Oxford University Press.

Tuten, Tracy L. 2008. Advertising 2.0: Social Media Marketing in a Web 2.0 World: Social Media Marketing in a Web 2.0 World. ABC-CLIO.

Venhaus, J. 2010. "Why Youth Join Al-Qaeda.” Report of the U.S. Institute of Peace. Retrieved from: www.usip.org

Wallace, Kelly. 2014. "Slenderman Stabbing Case: When can Kids Understand Reality vs. Fantasy?" CNN. Retrieved from: http://www.cnn.com/2014/06/03/living/slenderman-stabbing-questionsfor-parents/

Wang, Jing, and Bobby J. Calder. 2006. "Media Transportation and Advertising." Journal of Consumer Research 33 (2): 151-162.

Weimann, Gabriel. 2008. "Online Terrorists Prey on the Vulnerable.” Yale Global Online 5. Retrieved from: http://yaleglobal.yale.edu/content/onlineterrorists-prey-vulnerable

Wheeler, Christian, Melanie C. Green, and Timothy C. Brock. 1999. "Fictional Narratives Change Beliefs: Replications of Prentice, Gerrig, \& Bailis with mixed corroboration." Psychonomic Bulletin and Review 6 (1): 136-141.

White, Claire M., Michaela Gummerum, and Yaniv Hanoch. 2015. “Adolescents' and Young Adults' Online Risk Taking: The Role of Gist and Verbatim Representations." Risk Analysis 35 (8): 1407-1422.

Wilson, Carolyn, Alton Grizzle, Ramon Tuazon, Kwame Akyempong, and Chi Kim Cheung. 2013. Media and Information Literacy Curriculum for Teachers. UNESCO. Retrieved from: http://unesdoc.unesco.org/images/0019/001929/192971e.pdf

Wyer Jr, Robert S., and Rashmi Adaval. 2004. "Pictures, Words, and Media Influence: The Interactive Effects of Verbal and Nonverbal Information on Memory and Judgments." In The Psychology of Entertainment Media, edited by Jessica Shrum, 137-159. Mahwah, NJ:Erlbaum.

Yang, Jeff. 2014. "Between Two Ferns Boosts Traffic to Obamacare Website-But Will it Last?" Wall Street Journal, March 12. Retrieved from: http://blogs.wsj.com/speakeasy/2014/03/12/between-two-ferns- booststraffic-to-obamacare-website-but-will-it-last/ 
S. Gretter, A. Yadav \& B. Gleason / Journal of Media Literacy Education 2017 9(1), 1 - 21

Zipes, Jack. 2013. Creative Storytelling: Building Community/Changing Lives. New York: NY: Routledge.

Zelin, Aaron Y. 2015. "Picture or it Didn't Happen: A Snapshot of the Islamic State's Official Media Output." Perspectives on Terrorism 9 (4).

Available: http://www.terrorismanalysts.com/pt/index.php/pot/article/ 